\title{
Parents' Perspectives on the School Experiences of Children with Cancer
}

\author{
Mark A. Chesler and Oscar A. Barbarin, The University of Micbigan
}

\begin{abstract}
Interviews with 59 parents of school age children with cancer indicate problems children encountered in returning to school: missing significant amounts of school due to illness and treatments, teasing by classmates and peers, and strained relations with teachers. Most parents report that despite missing much school their child was caught up with schoolwork, suggesting that academic difficulties are not paramount. Most parents also report receiving substantial help from sympathetic and competent educators. However, parents also indicate that some teachers were insensitive to their child's condition, while others were overprotective, suggesting the need for a delicate balance in defining appropriate teacher behavior. A responsive yet normalizing school environment can be facilitated by vigorous and proactive partnerships among the medical staff, family, and school system.
\end{abstract}

Recent medical advances have dramatically extended the lifespans of children with cancer and have permitted some children to be "cured" (American Cancer Society, 1982; National Cancer Institute, 1981). More of these children and their families must now deal with problems of "reentry" (Kagen-Goodheart, 1977), the steps required to resume relatively normal family and community functioning after a diagnosis of cancer. Since school is a central extra-familial environment for most children, school re-entry signals that children with cancer are more normal than not, despite their struggle with illness. Physicians, nurses, and others now stress the necessity for ill children to return to school as soon as possible and to participate as fully as possible in regular school activities. 
Although the vast majority of children with cancer can and do attend school during and after their treatment, not all do so on a regular basis. Some children appear to become school-phobic, although this reaction appears increasingly rare as medical staffs and parents have become more sophisticated (Barbarin \& Chesler, 1983; Futterman \& Hoffman, 1970; Lansky, Lowman, Vats, \& Gyulay, 1975). Others are so ravaged by the disease and its treatment (vigorous chemotherapy and radical surgery) that they cannot attend school consistently or, when they can, require a specialized school environment and program. Some children, of course, die without completing a normal school program.

Parents often are concerned about the problems their ill child will encounter upon return to school. The focus of these concerns ranges from the possibility of contracting an infectious disease (while the child is in an immuno-suppressed state due to treatment) to lowered academic performance and stigmatization by others. Several studies stress the importance of others' reactions to the ill child as a major component of adaptation to illness and to future opportunities (Cyphert, 1973; Greene, 1975; Katz, 1980). Social isolation and peer teasing of an amputee or of a child bald from chemotherapy, for example, represent problems frequently addressed in the literature on school re-entry (Katz, Kellerman, Rigler, Williams, \& Siegal, 1976; Moore \& Triplett, 1980; Zwartjes, 1978). Peers may fear contagion or be uncertain about how to respond to what looks like a "special person." Teachers, too, may react stereotypically (Cyphert, 1973; Kaplan, Smith, \& Grobstein, 1974) by isolating (Feldman, 1980) or even ridiculing him or her. They may withdraw emotionally or ignore the child, perhaps out of fear or confusion about how to behave appropriately. Some teachers, concerned about the emotional and physical drains imposed on a child struggling with a potentially fatal illness, may inappropriately lower academic requirements (Katz, 1980).

Not only may researchers, educators, and peers exaggerate these potential problems; so may parents. If worried parents buffer and protect their children too much their youngsters may receive a message of their extreme vulnerability and may become inappropriately hesitant and cautious (Lansky et al., 1975; Spinetta, Spinetta, Kung, \& Schwartz, 1976). At times, of course, parents and professionals may go too far in the opposite direction; by denying that problems exist, parents may fail to adequately protect their children medically and prepare their children emotionally. Indeed, it appears that children will need preparation to face ignorance, inflexibility, or even cruelty on the parts of peers, neighbors, or the school staff. 
Deasy-Spinetta and Spinetta (1980) report that teachers described school age cancer patients as not different from typical students in their classes on several important dimensions: willingness to attend school, play habits, and dependency. However, teachers also reported that students with cancer attended school less frequently, had greater difficulty concentrating, and had less energy than their physically healthy peers. Moreover, they described the ill children as "inhibited, less active, less willing to try new things, and less likely to express either positive or negative emotions" (Deasy-Spinetta \& Spinetta, 1980, p. 89). These perceptions probably are most accurate in describing children who are in the midst of active and perhaps debilitating treatment. As treatment regimens ease, children who are in remission and doing well behave and often are seen more like all other children. In a study of 117 long-term survivors of childhood cancer, Koocher and O'Malley (1981) indicate that although many of these young adults (some still students) had mild adjustment problems, relatively few encountered serious emotional difficulty or needed psychiatric assistance. There is a double message in most of these and other reports: Adjustment problems and reactions do occur, but these reactions do not occur very often in very serious terms.

This paper examines aspects of the family's struggle to negotiate and influence the quality and character of the child's experience in school. Specifically, we examine parents' reports of the school problems they and their ill child experienced, and the ways in which parents perceived school staff members' handling of these problems.

\section{Methods}

The data discussed here were gathered as part of a larger study of the stresses and coping patterns of families of children with cancer (Chesler, Barbarin, Chesler, Hughes, \& Lebo-Stein, 1981). In that study 55 families were sampled from a pool of several hundred families of children with cancer treated at a major midwestern medical center and children's hospital. Ninety-five parents of children with cancer were interviewed, of whom 75 were parents of living children and 20 were parents of deceased children. All interviews took place in the homes of families and each parent was interviewed separately. Interviewers were graduate and undergraduate students who had previously worked in the hospital with ill children and who had received special training to conduct the interviews. The sample was deliberately stratified on the 
basis of the type of cancer and the age and life-status of the child, so that it would be broadly representative of the range of families experiencing childhood cancer.

The study utilized both open-ended and close-ended questions, with preplanned probes to clarify initial responses. The interview covered such issues as the nature of the diagnosis and prognosis, course of illness, problems the family encountered, ways in which family members coped with the illness and its impact, and interactions with the medical system, friends, and community institutions. With regard to school re-entry, parents were asked to indicate any problems they or their children experienced, and whether the illness affected attendance, motivation, or performance. Parents also were asked to rate educators' helpfulness (on a 5-point scale, ranging from "very helpful" to "not helpful"), and to specify staff behaviors that were and were not helpful. When each interview was completed, the informant was asked to fill out a 6-page questionnaire covering the same topics in a prestructured format and to mail it back to the investigators: Ninety percent of these questionnaires were returned.

Thirty-five of the 55 families ( 59 of the 95 parents) had living children of school age at the time of the interview, and the data reported herein is limited to these parents. These parents were evenly distributed across groups earning (1) less than $\$ 15,000$ /year, (2) between $\$ 15,000$ and $\$ 25,000 /$ year, and (3) over $\$ 25,000 /$ year. Similarly, there was an even distribution with regard to parents completing (1) a high school education or less, (2) some college, and (3) a college degree or more. Approximately half the parents in the school age sample had children over 11 years of age (between 11 and 18 years), and half had children under 11 years of age (between 6 and 11). Further details on this study, including data from adolescents and teachers, are reported elsewhere (Barbarin \& Chesler, 1983).

\section{Results}

\section{Parents' Vlews of Schooling Problems}

Parents were asked to identify any problems their child faced when he or she returned to school. Table 1 indicates that 30 of the 59 parents (51\%) with school age children with cancer reported that their child experienced problems. The two problems mentioned most often included missing much school and teasing or rejection by peers. 
Table 1. School Problems Reported by Parents of Children with Cancer

\begin{tabular}{lcc}
\hline Problems & $\begin{array}{c}\text { Number and Percentage of Parents } \\
\text { Reporting School Problems } \\
\%^{\mathrm{a}}\end{array}$ \\
\hline Mentioned any problem & 30 & 51 \\
Teasing by peers & 22 & 37 \\
Missed much school & 18 & 31 \\
Relations with teachers & 7 & 12 \\
\hline
\end{tabular}

${ }^{a}$ Since some parents mentioned more than one problem, the total percentage equals more than $100 \%$.

The definition of missing "much" schooling used here is at least a few days or more per month, over the course of years. Children who missed several days or even weeks at diagnosis and the beginning of treatment, but who were able to attend school regularly after that, were not interpreted as missing much school. Parents' reports that the child missed much school were related significantly to the child's medical progress and treatment vigor or complexity. As one might expect, children who had relapsed missed "much" school more often than did children who stayed in remission (64\% versus $26 \%: X^{2}=5.6, d f=1, p .<$ $.05)$ and children who had been hospitalized more than three extended times were more likely to have missed much school than those children who were hospitalized less often ( $58 \%$ versus $13 \%: X^{2}=12.2, d f=1, p .=$ $<.01)$. However, parents who reported that their child missed much school were no more likely than other parents to report that their child was not caught up with school or that they experienced other problems, including teasing. It seems clear that while missing school may be a common experience for children with cancer, they do not all miss a lot of school; only a relatively small minority does. Moreover, whatever the impact is of missing much school, it does not, in and of itself, lead to a host of academic problems.

A second problem many parents mentioned with regard to their child's schooling concerned teasing, avoidance, or rejection by peers. Over two thirds $(22 / 30)$ of the parents reporting problems with schooling indicated that teasing by peers had been a concern. Consider some of the following comments by parents:

There was some teasing. But he didn't want me to talk with the teacher or do anything about it. That would make it worse, he thought. 
There was one turkey who really teased him a lot. He hit him and knocked out one of his teeth and that stopped it.

Teasing is a typical event in the classroom; perhaps it even is normal. It is generally focused on children who are "different," and children reentering school with visible disabilities certainly look different. Radiation and chemotherapy often resulted in visible hair loss and weight gain or loss as well as facial puffiness, and surgical removal of an arm or leg required either a prosthesis or the use of crutches. Such conditions, as well as sporadic absence or special academic treatment, made these children easy targets for teasing. However, some peers' reactions went beyond teasing to obvious cruelty and rejection of the child with cancer. As some parents commented:

She was treated like a leper.

The kids would make fun of him when he had no hair and when he was on medication and blew up like a balloon. There were remarks made to him that he was going to die.

In addition to concern about peers' reactions, some parents were particularly troubled and angry at the reactions of a few other parents. Consider the following comments, and the potential relationship between these parents' actions and youngsters' teasing or other negative behaviors.

The children were told about it in school, and they weren't too upset. But some parents were upset because their kids came home and they were concerned that their friend was really, really sick. Anyone would be upset. But the parents got mad that the school had said anything about it; they felt that the school shouldn't have told the kids and upset them.

I did have some parents call me and tell me that they did not want my child in school, because they did not want their children to come down with cancer.

A problem mentioned by a small number of parents (thus not listed in Table 1) involved the siblings of the ill child. Recent research on the psychosocial aspects of childhood cancer stresses that it is a family disease in the sense that everyone in the family is likely to be affected by it. Moreover, of all family members, siblings often appear to be most "left out," to receive the least attention at home (Gogan, Koocher, Foster, \& O'Malley, 1977; Sourkes, 1980; Spinetta, 1978). Some parents expressed 
their concern about the school staffs lack of sensitivity to the ill child's siblings.

Her brother is often getting into fights because he can't stand the other kids teasing her ... about her hair and everything.

The school let me down when they didn't understand my sick kid's older brother. I mean, a nice boy like that, who's never done anything wrong before, suddenly acting out. You'd think they would have anticipated some changes and been on the lookout, or at least been more sensitive when it happened.

The little one feels he isn't getting enough attention at home, and he's right. I need some extra help from the school on this one.

These reports suggest that school problems are centered not only in the ill child (e.g., missing school), but also in the reactions of the child's teachers, peers, parents, and siblings. If all attempts to moderate the stress of school re-entry are directed toward the sick child, without attention to siblings and peers, significant sources of stress will remain unaffected and interventions will be incomplete and ineffective.

\section{Parents' Vlews of Help from the School Staff}

Table 2 indicates parents' responses to the question of whether school people were helpful to them in dealing with these problems. Over half $(55 \%)$ the 53 parents responding described school people as very or quite helpful, but another $45 \%$ described the staff as not helpful, a little helpful, or only somewhat helpful. Table 2 suggests that parents of junior and senior high school age children (over 11 years) were no more likely to report helpful responses from educators than were elementary school parents. Analysis of staff helpfulness by parental income level also failed to yield significant results.

However, more highly educated parents reported helpful responses from school people significantly more often than did parents with less education. School people may have responded differently to parents with more education, parents who were of the same or higher status as the educators. Perhaps parents with more educational experience were more assertive about asking for help for their children, or appreciated the help 
Table 2. Parents' Reports of the Helpfulness of School People, by Demographic and Other Factors

\begin{tabular}{|c|c|c|}
\hline Factors & $\begin{array}{l}\text { School Per } \\
\text { Very/Quite } \\
\text { Helpful (\%) } \\
(N=29)\end{array}$ & $\begin{array}{l}\text { Aelpfulness } \\
\text { Little } \\
\text { Helpful (\%) } \\
(N=24)\end{array}$ \\
\hline \multicolumn{3}{|l|}{ Students' Age } \\
\hline 11 or under $(N=28)$ & 47 & 53 \\
\hline Over $11(N=25)$ & \multicolumn{2}{|c|}{$\left(X^{2} 1.6, N S\right)$} \\
\hline \multicolumn{3}{|l|}{ Parents' Level of Education } \\
\hline College Graduate $(N=17)$ & 76 & 23 \\
\hline Some college $(N=17)$ & 34 & 64 \\
\hline High school or less $(N=16)$ & 38 & 62 \\
\hline$N A(N=3)$ & \multicolumn{2}{|c|}{$\left(X^{2}=10.9, d f=2, p<.05\right)$} \\
\hline \multicolumn{3}{|l|}{$\begin{array}{l}\text { Parental Satisfaction with } \\
\text { School Staff's Response to } \\
\text { Child }\end{array}$} \\
\hline Satisfied $(N=37)$ & 62 & 38 \\
\hline Not satisfied $(N=6)$ & 17 & 83 \\
\hline$N A(N=10)$ & 50 & 50 \\
\hline \multicolumn{3}{|l|}{$\begin{array}{l}\text { Child's caught up and doing } \\
\text { well in school }\end{array}$} \\
\hline Yes $(N=41)$ & 61 & 39 \\
\hline No $(N=6)$ & 33 & 67 \\
\hline NA $(N=6)$ & 33 & 67 \\
\hline
\end{tabular}

they did receive more than other parents did. Perhaps, too, the children of more highly educated parents were doing better in school to start with, and thus seen as "better bets" for educators to invest time and energy in. Parents who reported school people as very/quite helpful also appeared more often to be satisfied with the school's response to their child, although the number of cases in the not satisfied cells ( $n=1$ and 5) is too small to permit reliable quantitative analysis.

Helpfulness of school people may matter! Parents who felt their child was doing the same or better quality of work now than before the illness appear more likely to report school people as very/quite helpful, although the numbers of children rated by their parents as doing less well now $(n=6)$ is too small for reliable quantative analysis. With a larger sample, Feldman (1980) also reported that students with cancer from families with higher educational backgrounds were more likely 
than students from other families to improve their academic performance on re-entry to school. If higher educational background is related to parents' perception of helpfulness from the school, and if more helpfulness is related to the child's stable or even improved performance on re-entry, then this combination of findings makes good sense.

Children who were not doing well in school prior to their diagnosis sometimes had an especially difficult time catching up afterwards. In at least one case, involving a lower class teenager with osteogenic sarcoma, a mother felt her son's problems were compounded by a lack of help from the school.

My son was different from some others because he was a " $C$ " and " $D$ " student before he got cancer. When he came home from the hospital no one called the house. All the initiative had to be ours, and we had enough to deal with already. I guess they figured that since he was not a good student to begin with, they should not bother. Besides, in their minds he was dying already. I think the school gave up on him, and as a result he gave up on school. He stopped trying and dropped out.

School personnel often wonder how helpful they should try to be to the sick child, and how much they should extend themselves to the family (Barbarin \& Chesler, 1983). Uncertainty on these issues may prevent teachers and school administrators from taking the initiative to provide help or the most appropriate and useful form of help. Table 3 reports some things parents identified teachers as doing that were helpful and some that were not.

There appears to be a delicate tension or balance among some of these reported behaviors. If caring and giving special help is seen as positive, too much of it may be seen as overprotective. If treating the child as normal is positive, too much of that (in the face of nonnormality) may be seen as insensitivity. Van Eys captured this dilemma in the following terms (1977, p. 168):

If the cancer were ignored by well-meaning people, the child's reality would be distorted and he would not be accepted as the person he is. On the other hand, when the cancer is made the overwhelming concern, the "normal" in the child that wants to be recognized is ignored. Either produces despair. 
Table 3. Parents' Reports of What the Teacher Did That was Helpful or Not Helpful



Even the best prepared and experienced teachers walk a thin line in deciding how to be truly helpful to students and their families. Teachers new and inexperienced to these issues may be anxious and fearful, and either duck and ignore issues or pay too much attention to imagined difficulties and problems. These responses, while understandable, also represent what many adults experience when facing and interacting with people with cancer (Wortman \& Dunkel-Schetter, 1979). If teachers are isolated from the family, unable to create or respond to effective conversations about the child's condition and needs in school, their discomfort, and these problems, are likely to be exacerbated.

\section{Conclusions and Recommendations}

Many recent reports of the school re-entry problems of children with cancer and other chronic illnesses argue for normalization of the child's environment and experience, and for direct and well-coordinated information and communication shared among various persons and institutions. This emphasis is consistent with the intent of P.L. 94-142, the Education for All Handicapped Children Act, although it seldom has been applied to children with cancer and other illnesses. But normalization also requires pro-active attention to the problems ill children are likely to face. Teachers anticipating unusual absences from school can take the initiative in delivering homework assignments personally to the home-bound or hospitalized child, or in sending them along with a trusted and caring peer. With the family's (and child's) permission and participation, they can mobilize a peer support system and plan and prepare peers for the child's return to school. 
It requires concerted action to avoid the stigma and negative social reactions that unduly single out ill children and that deny them access to positive peer contacts and school resources. Thus, teachers often must challenge their own and their students' stereotypes and behaviors which ipso facto suggest that ill children are "different," incapacitated, or doomed to failure in school. In some cases, of course, lowered or relaxed requirements and special care or treatment are necessary and appropriate. Normalization does not mean denying the seriousness of these children's conditions, nor of physical or psychological differences that may affect the administration of classroom rules and regulations. Most importantly, it does not mean treating ill children like all other children; in one specific example reported by parents it does not mean requiring that the hospitalized child take his final examination at the same time and place as all other students in the class. These issues obviously are more delicate, and in some ways even more critical, when the ill child has been socially or academically marginal prior to the illness.

The school staff is unlikely to be successful in aiding the child's reentry to school unless good communication is established between the family and the school. This is an especially crucial step in the attempt to deal with siblings' concerns; without family school coordination teachers may not even be aware that a student has a sibling with cancer, and thus are unprepared for sudden behavior changes. Moreover, regular and accurate updates on the ill child's progress, appointment schedules, special needs, and long-term prognosis may do much to ease teachers' anxieties and to permit development of an appropriate educational approach to re-entry.

The medical staff also has a critical role to play in educating parents and school staffs and in facilitating coordination of services to the ill child. Recent reports emphasize ways in which the medical staff, too, may take the initiative in easing the child's re-entry to school (Cyphert, 1973; Greene, 1975; Moore \& Triplett, 1980; National Cancer Institute, 1980; Pearse, 1977). Some medical centers specializing in the treatment of children have begun to sponsor in-service programs, workshops, and annual conferences for educators (Baskin, Saylor, Furay, Finch, \& Carek, 1983; Deasy-Spinetta, 1981). However, even such special conferences do not attend to the daily, weekly, or monthly problems of information transfer and coordination.

If the school and medical bureaucracy fail to establish ongoing and pro-active programs, parents must manage such coordination and monitoring by themselves. Families facing considerable stress and turmoil may just be too overburdened to fulfill this responsibility alone. 
All parties to this challenge-parents, schools staffs, and medical staffshave to take the initiative if chronically ill children are to regain a normal school life.

\section{References}

American Cancer Society. (1982). Cancer facts and figures. New York: Author.

Barbarin, O., \& Chesler, M. (1983). Children with cancer: School experiences and views of parents, educators, adolescents and physicians, Oakwood, IL: Eterna Press.

Baskin, C., Saylor, C., Furay, W., Finch, A., \& Carek, D. (1983). Helping teachers help children with cancer: A workshop for school personnel. Children's Health Care, 12(2), 78-83.

Chesler, M., Barbarin, O., Chesler, J., Hughes, D., \& Lebo-Stein, J. (1981). Role of informal networks and medical care organizations in belping families cope with cbildhood can-

cer. Ann Arbor, Center for Research on Social Organization (Working paper \#243).

Cyphert, F. (1973). Back to school for the child with cancer. Journal of School Health, 43, 215-217.

Deasy-Spinetta, P. (1981). The school \& the child with cancer. In J. Spinetta \& P. DeasySpinetta (Eds.), Living with childhood cancer (pp. 153-168). St. Louis: C.V. Mosby.

Deasy-Spinetta, P., \& Spinetta, J. (1980). The child with cancer in school: Teachers' appraisal. American Joumal of Pediatric Hematology/Oncology, 2, 89-94.

Feldman, F. (1980). Work and cancer bealth bistories (abridged). Oakland, CA: American Cancer Society.

Futterman, E., \& Hoffman, I. (1970). Transient school phobia in a leukemic child. Journal of the American Academy of Child Psychology, 9, 477-493.

Gogan, J., Koocher, G, Foster, D., \& O’Malley, J. (1977). Impact of childhood cancer on siblings. Health \& Social Work, 2, 41-57.

Greene, P. (1975). The child with leukemia in the classroom. American Journal of Nursing, 75, 86-87.

Kagan-Goodheart, L. (1977). Re-entry: Living with childhood cancer. American Journal of Ortbopsychiatry, 47, 651-658.

Kaplan, D., Smith, A., \& Grobstein, R. (1974). School management of the seriously ill child. Journal of School Health, 44, 250-254.

Katz, E. (1980). Illness impact and social reintegration. In J. Kellerman (Ed.), Psychological aspects of cbildhood cancer (pp. 14-46). Springfield, IL: Charles C Thomas.

Katz, E., Kellerman, J., Rigler, D., Williams, K., \& Siegel, S. (1976). School intervention with pediatric cancer patients. Joumal of Pediatric Psychology, 2(2), 72-76.

Koocher, G., \& O'Malley, J. (1981). The Damocles syndrome: Psychosocial consequences of surviving childhood cancer. New York: McGraw-Hill.

Lansky, S., Lowman, J., Vats, T., \& Gyulay, J. (1975). School phobia in children with malignant neoplasms. American Journal of Disabled Cbildren, 129, 42-47.

Moore, I., \& Triplett, J. (1980, August). Students with cancer: A school nursing perspective. Cancer Nursing, pp. 265-271.

National Cancer Institute. (1980). Coping with cancer. Bethesda, MD, U.S. Department of Health and Human Services, National Institute of Health Publication No. 802080. 
National Cancer Institute. (1981). Decade of discovery: Advances in cancer research: 19711981. Rockville, MD: U. S. Department of Health and Human Services, National Institute of Health Publication No. 81-2323.

Pearse, M. (1977). The child with cancer: Impact on the family. Journal of School Health, 47, 174-179.

Sourkes, B. (1980). Siblings of the pediatric cancer patient. In J. Kellerman (Ed.), Psychological aspects of childhood cancer. Springfield, IL: Charles C Thomas.

Spinetta, J. (1978). Communication patterns in families dealing with life-threatening illness. In O. Sahler (Ed.), The child and death. St. Louis: C.V. Mosby.

Spinetta, J., Spinetta, P., Kung, F., \& Schwartz, D. (1976). Emotional aspects of cbildhood cancer and leukemia: $A$ bandbook for parents. San Diego: Leukemia Society of America.

Van Eys, J. (1977). The outlook for the child with cancer. The Journal of School Health, 47, 165-169.

Wortman, C., \& Dunkel-Schetter, C. (1979). Interpersonal relationships and cancer: A theoretical analysis. Journal of Social Issues, 35(1), 120-155.

Zwartjes, W. (1978). Education of the cbild with cancer. Paper presented at the American Cancer Society National Conference on the Care of the Child with Cancer, Boston. 